\title{
Financial Hedging and Sustainability Modeling Considering Uncertainties: A Case Study of Ethanol Supply Chain
}

\author{
Awudu Iddrisu ${ }^{1}$, Jun Zhang ${ }^{2}$, Atif Osmani ${ }^{3}$, Khalid Bachkar ${ }^{4}$, James Malm ${ }^{5} \&$ Mariama Yakubu ${ }^{6}$ \\ ${ }^{1}$ School of Business, Quinnipiac University, USA \\ ${ }^{2}$ School of Engineering, Californian Baptist University, USA \\ ${ }^{3}$ Paseka School of Business, Minnesota State Univery, USA \\ ${ }^{4}$ California State University Maritime Academy, USA \\ ${ }^{5}$ Department of Finance, College of Charleston, USA \\ ${ }^{6}$ Department of Emergency Management, University of New Haven, USA \\ Correspondence: Iddrisu Awudu, School of Business, Quinnipiac University, 275 Mt. Carmel Avenue, Hamden, \\ Ct, 06518, USA. Tel: 1-203-582-7906. E-mail: Iddrisu.awudu@quinnipiac.edu
}

\author{
Received: February 23, $2015 \quad$ Accepted: March 23, $2015 \quad$ Online Published: May 31, 2015 \\ doi:10.5539/jms.v5n2p1 URL: http://dx.doi.org/10.5539/jms.v5n2p1
}

\begin{abstract}
Incorporating financial hedging and sustainability in a supply chain is crucial for profit maximization or cost minimization. Uncertainties in supply chain develop into risks that affect the profit maximization or cost minimization expectations. In order to deliver end-products to destination markets in an efficient and effective manner, a supply chain management model that incorporates risk management measures is crucial. This paper develops a mathematical model that integrates hedging strategies in a biofuel supply chain with a corn and cellulosic raw material production setting. The paper is structured by first developing an optimization model considering maximization of the supply chain profit with risk without hedging for both corn and cellulosic biorefinery plants. Secondly, we incorporate sustainability concepts including environmental and social aspects. Finally, a heuristic method is developed for the hedging and a two-stage stochastic linear programming with Multi-cut Benders Decomposition Algorithm (MBD) is used to solve the problem. A case study in North Dakota is adopted for this study. The results for hedging and non-hedging are compared and sensitivity analyses conducted.
\end{abstract}

Keywords: hybrid-generation biofuel supply chain, risk, hedging, two-stage stochastic linear programming, Multi-cut Benders Decomposition

\section{Introduction}

Risk management and sustainability are crucial aspects of the supply chain that have gained enormous attention by researchers and practitioners. Uncertainties complicate the operations in a supply chain but provide opportunities to maximize operational efficiencies and supply chain performance. Sustainability on the other hand defines an environmentally friendly and socially responsible supply chain strategy. The motivation for this paper is to improve supply chain by managing risks and incorporating sustainability to meet supply chain efficiency (cost) and effectiveness (value). We first define the term Renewable Energy Supply Chain (RESC) which is a combination of corn-based and cellulosic-based biofuel supply chain. Both cellulosic and corn ethanol plants are considered because of the importance of these raw materials to the current biofuel industries. The reason is that the expanded Renewable Fuel Standard (RFS) (referred to as RFS2) requires the annual use of 9 billion gallons of biofuels in 2008. This mandate has been expanded to 36 billion gallons annually in 2022, of which no more than 15 billion gallons can be ethanol from corn starch, and no less than 16 billion must be from cellulosic biofuels (Schnepf \& Yacobucci, 2013; Tang \& Tomlin, 2008; Ahuja et al., 1993). It is therefore important to consider both corn and cellulosic feedstock.

The importance of the RESC is to meet the Renewable Fuel Standards (RFS) for 2022, where approximately 32 billion-gallons of ethanol are expected to be produced, with 15 billion-gallons from corn ethanol and 16 billion-gallons from advance ethanol such as cellulosic. Uncertainties in the biofuel supply chain are realized in every stage of the decision making process. Some of the uncertainties in the RESC renewable energy supply chain 
(RESC) include, but not limited to: (1) price of ethanol, (2) cost of feedstock, (3) transportation cost of raw materials and end-products, (4) conversion rate, (5) production cost, and (6) demand of end-product. Not incorporating uncertainties in the biofuel supply chain decision making results in profit variation from the expected or targeted profit. It is used to protect portfolio volatility due to market fluctuation during budget, economic, and political or corporate turmoil. The basic rule in hedging is that the risk of a loss in any portfolio is offset by the gains in the futures or options position in which the same commodity or its derivative is sold or purchased. Although there are many kinds of risks within the supply chain, operational and financial risks are frequently discussed. Examples of some of these risks are supply, demand, process, commitment, intellectual property, behavioral, economic, and political risks (Titodiya, 2010). These risks can be categorized into financial, operational, marketing, corporate, and other types of risks.

Research in risk management, especially hedging in biofuel supply chain is limited. This makes it important to develop optimization models that effectively integrate hedging decisions in the supply chain decision process. The RESC model for hedging provides advantages such as flexibility for multiple supply sources and low cost for cellulosic feedstock. The importance is to provide supply chain visibility and managed expectations of profits or cost. Therefore the direction of this paper is to develop an optimization model that incorporates hedging decisions in the RESC. Research novelties such as: 1) developing a heuristic method for the hedging; 2) modeling the corn feedstock and ethanol price uncertainties as Mean Reversion (MR); and 3) developing a hybrid biorefinery supply chain which consists of corn and cellulosic feedstock biorefinery plants. The next section reviews the relevant literature in hedging.

\section{Literature Review}

Hedging strategies are employed through some form of transactions designed to minimize exposure to an unwanted business risks (Huchzermeier \& Cohen, 1996). The first part of the literature in this paper considers the application of financial hedging tools in a supply chain setting. Li et al. (2009) investigate the role of forward commitments and option contracts between a seller (supplier) and a buyer (retailer) in the presence of asymmetric information options contracts. The objective is to optimize supplier selection to hedge against these disruptions by using a two-stage stochastic program. Results from the case study indicate an effective trade-off between cost and risk by supporting improved decision making. Financial hedging strategies as defined and illustrated in Yun et al. (2009), use an integrated biorefinery process to tackle the issue of diversifying products as well as raw materials. The objective of the paper is to minimize the purchase risk of raw materials using futures contract. The results indicate decreasing profit variability and increasing refinery operational flexibility. Similar approach with a discussion on the advantages of real options in resourcing partners contingent on demand and/or exchange rate scenarios are illustrated in Bish and Suwandechochai (2010). A forward hedging strategy is used by Arnold and Minner (2010) in an option pricing framework for demand and market uncertainties. The paper's objective is to adopt a stochastic programming for both linear and non-linear solution to investigate the performance of the model The results indicate a better performance of the stochastic case as compared to the deterministic case. Gupta and Maranas (2010) propose a forward contract and options derivatives to price derivatives like the European options. The paper uses a stochastic framework and solves the problem using different algorithms. The results indicate a more stable approach or cost minimization using emission cost with uncertainty than without uncertainties. One of the works that has integrated hedging in the decision process in other supply chains includes Huchzermeier and Chen (1996). This paper examines options under financial and operational hedging scenario. A stochastic dynamic programming approach is used where the uncertain exchange rate is assumed to follow a diffusion process. Options are then used to model the process design and manufacturing. The paper concludes with a balanced hedging result for both the operational and financial hedge with a bias towards the financial hedging approach. Although papers such as Inderfurth and Kelle (2011), Li et al. (2009), Wu and Chuang (2010), and Yun et al. (2009) have discussed other combined hedging methods in a way, none has been contributed within the biofuel supply chain.

Sustainability needs to be incorporated in the decision making process when considering the biofuel supply chain for either profit maximization or cost minimization (Zhu et al., 2013). The three main sustainability concepts that need to be considered are economic, environmental, and social responsibility. Although some literature have considered the integration of economic and social responsibility, such as Cruz (2013), and economic and environmental sustainability by Sundarakani et al. (2010), not much attention has been channeled towards the integration of the three sustainability concepts. So far the paper by You et al. (2011) considered a cellulosic biofuel supply chain which combines the three sustainability concepts with life cycle assessment (LCA). Nonetheless, no uncertainties are incorporated in the model presented.

Although several researches have considered supply chain optimization, the studies have been limited to the levels 
of: (1) supply chain network optimization, (2) maximization of profit, and (3) minimization of cost (e.g., Eksioglu et al., 2009; Kim et al., 2011; Gronalt \& Rauch, 2007; Zhang et al., 2013; Bazaraa \& Sherali, 1981). There are also literature such as Cucek et al. (2012) that incorporated economic and environment sustainability by maximizing the supply chain profit and calculating the environmental effect through classification into direct and indirect footprints. Articles that have examined a combination of the sustainability concepts are as follows: Zamboni et al. (2009) considered a Mixed Integer Linear Programming (MILP) static model with spatial characteristics that are explicit for the design of a bio-fuel supply chain at the strategic level. The paper further accounts for the concurrent minimization of cost while incorporating environmental sustainability concepts in terms of the GHG emissions. Mele et al. (2009) addressed a planning problem of a biofuel supply chain with both environmental and economic integration. An optimization solution method based on the bi-criterion MILP model was proposed for minimization of the total cost and its environmental concerns simultaneously. The results further analyze the performance over the entire life cycle of sugar and ethanol. You and Wang (2011) integrated the successive optimization of a biomass-to- liquids supply chain based on life cycle optimization. The model is built based on economic and environmental criteria. The results concluded an economically sound and environmentally friendly biomass processing supply chain. In the area of carbon emission trading, Cong and Wei (2010) study the potential impact of the introduction of Carbon Emission Trading (CET) on China's power sector and discuss the impact of different allocation options of allowances. An agent-based modeling approach is used to solve the resulting problem. The paper concludes that incorporating the CET internalizes the environment cost as well as increases the average electricity price. Further results analyses indicate transfer carbon price volatility to the electricity market is realized which increases the electricity price volatility. A full-infinite interval-stochastic mixed-integer programming (FIMP) is implemented by Zhu et al. (2013) for planning carbon emission trading under dual uncertainties. The developed FIMP is applied to a real case study for managing carbon dioxide (CO2) emissions with trading scheme of Beijing's electric power system (EPS). The results show that the solutions for energy supply, electricity generation, carbon-quota allocation, and capacity expansion are not only needed but incorporated with policies and assessing economic impacts.

The contribution for this paper is as follows:

We developed a mathematical model integrating hedging andsustainability in a biofuel supply chain profit maximization problem.

(1) Developed a combination of corn and cellulosic feedstock biofuel supply chain

(2) Incorporated volatility in corn feedstock and ethanol prices and uncertainties in ethanol price, corn price, and ethanol demand prices

(3) Model the ethanol price using Mean Reversion (MR) model which reflects a random process and indicate a practical case

(4) Use the Multi-Benders Decomposition Algorithm to solve the proposed stochastic model due to the number of scenarios, problem tractability, computational time and problem size

(5) Conduct sensitivity analysis on corporate social responsibility, hedging using heuristic, and provide further managerial insights on GHG emission

The rest of the paper is organized as follows. Section 3 presents the problem statement. Section 4 provides the mathematical model, generating the price uncertainties, and evaluating the uncertainty parameters. In section 5 , the solution technique used is outlined. Section 6 presents the case study. Section 7 then summarizes the results and analyses. Final conclusions and further research are outlined in section 8.

\section{Problem Statement}

In this work, a corn and cellulosic combined biofuel supply chain is studied. There are two types of biomass feedstock considered: first generation and second generation. The representative supply chain diagram for both the cellulosic and corn feedstock is illustrated in Figure1. The first generation consists of corn and the second generation cellulosic feedstock. The supply chain network consists of raw material supply sources, warehouses or pre-treatment facilities, biorefinery plants, and demand zones. Supply sources are responsible for providing the raw materials which are corn and cellulosic feedstock. Warehouse or pre-treatment facilities prepare the raw materials into a suitable form before being transported to the biorefinery plants. The biorefinery plants convert the pre-treated raw materials into end-products, which is biofuel. The demand zones are aggregated at the county levels. There are $\boldsymbol{i}_{\boldsymbol{c}}$ number of raw material sources for corn feedstock, and $\boldsymbol{i}_{\boldsymbol{m}}$ sources for cellulosic feedstock. Warehouse or pre-treatment plants for the respective feedstocks are $w_{c}$ and $w_{m}$. The number of biorefinery plants is $\boldsymbol{k}_{c}$ for the corn ethanol and $\boldsymbol{k}_{\boldsymbol{m}}$ for the cellulosic ethanol plants. The end-product which is biofuel is represented by 
$c_{e}$ and $m_{e}$ for corn and cellulosic ethanol respectively. Finally, multi-time period consisting of 12-month horizon is adopted for this work.

Uncertainties such as prices of corn and cellulosic feedstock and prices of end-products are very common in RESC. In order to optimize the supply chain decisions, such as the amount of feedstock purchased, biomass pre-treated, amount of ethanol produced, production capacity of biorefinery plants, and the amounts of ethanol shipped from biorefinery to demand points, two-stage stochastic programming models are applied as discussed in Gupta and Maranas (2003). However, those models do not consider strategies to avoid the risk of having negative or low profit. In order to avoid extreme profit lost, hedging strategy is needed. Therefore, the main objective of this work is to maximize the expected profit within the entire supply chain setting and hedge the risk of obtaining low profit.

Mean reversion is used to model the prices of the feedstock and end-products. This assumption is used because most commodity prices exhibit high and low prices for a temporary period, and then the prices will move or shift to the average prices over time (Bessembinder et al., 1995). This is implemented from the data set obtained from the Iowa University Energy Research Group. The end-products are sold by using futures to reduce profit variability and provide some form of hedging. The corn biomass purchasing mechanism is based on a heuristic hedging strategy since corn as a commodity has high price volatility. In order to reduce the price variability and hedge against future uncertainties, the corn is procured at a futures price. The cellulosic feedstock is purchased at a spot price since no variability is assumed for its price. The heuristic method uses the mean reversion model to generate sample data for both the corn spot and futures prices. A method of buying corn feedstock using the spot price is used if futures price is greater than $y$ times the mean of the sample price generated. This characterizes a mean of an additional $x \%$ increase in each scenario. Similarly, the future price is opted if the spot price is greater than the $y$ times the mean of the sample price generated.

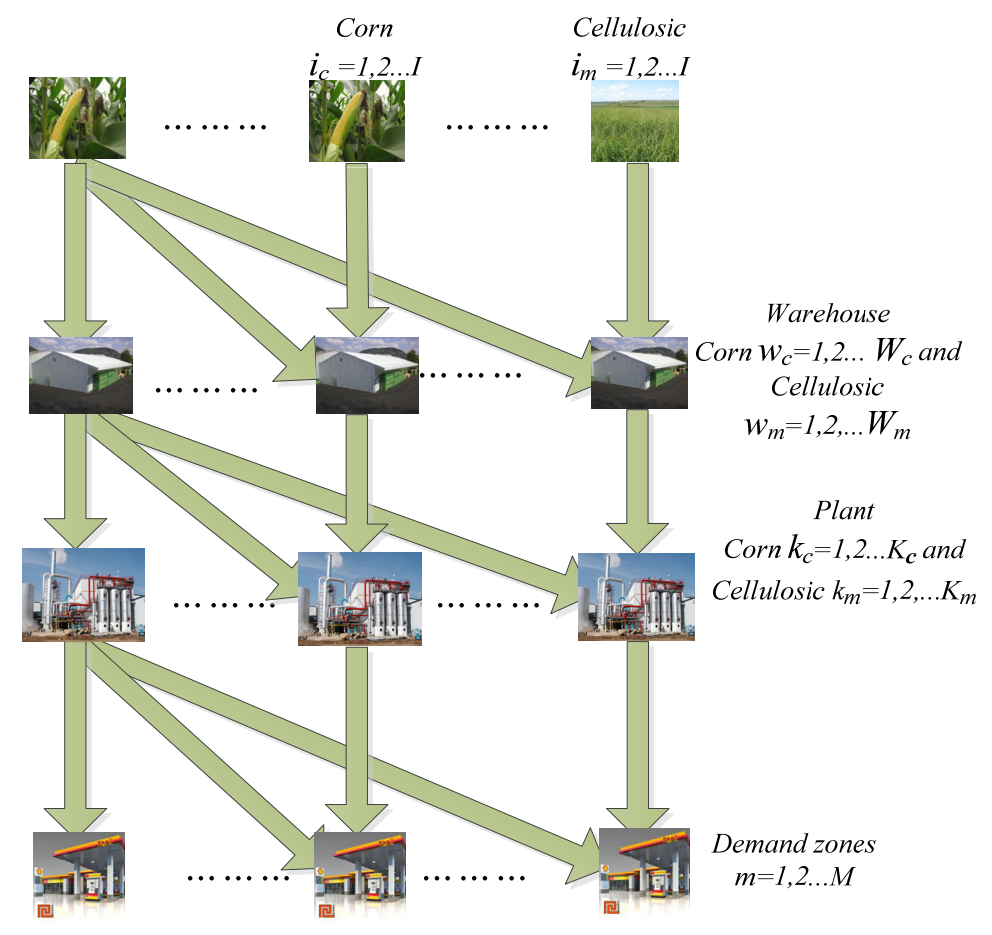

Figure 1. General supply chain structure

\section{Mathematical Model}

In this section, a mathematical model (see appendix A) is first proposed to incorporate hedging and a subsequent model is developed to integrate sustainability. The corn and cellulosic ethanol that are produced are sold on the spot market, while hedging involves buying corn feedstock using futures or spot based on the heuristic method developed. Cellulosic raw material is traded at the spot price concurrently. Essentially the ethanol produced from both the corn and cellulosic markets are sold using a futures position. Sustainability involves the incorporation of 
social and environmental aspects. The social sustainability considers corporate social responsibility while the environmental sustainability integrates greenhouse gas (GHG) emission.

\subsection{Objective Function for Corn and Cellulosic Ethanol}

The proposed model is solved to optimality for both the cellulosic ethanol and corn ethanol supply chain. The proposed model therefore has two objective functions, namely: 1) maximization of profit for corn ethanol and 2) maximization of profit for cellulosic ethanol. Z1 and Z2 represent the objective function of corn and cellulosic supply chain respectively.

\section{Profit for corn supply chain}

The objective for the corn ethanol supply chain is profit maximization (i.e. revenue - cost) and it is provided as:

$\mathrm{Z}_{1}=$

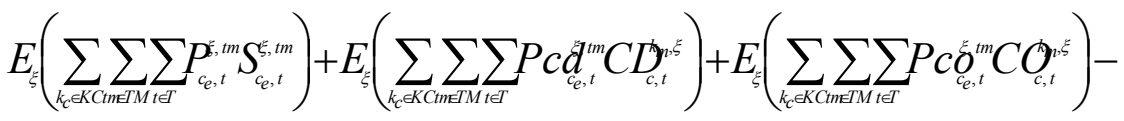

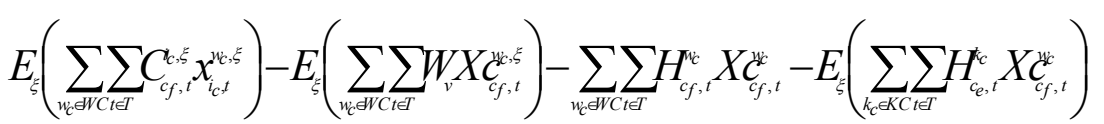

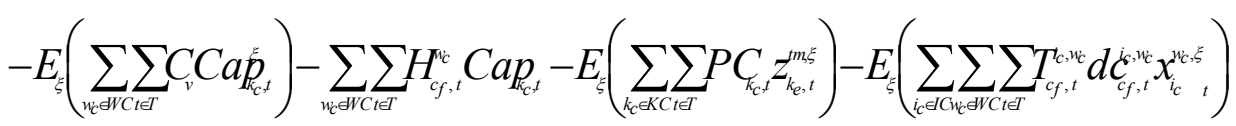

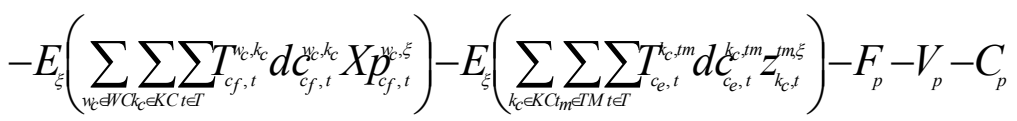

The different components of the equations are for the corn ethanol supply chain and are respectively explained as follows: revenue of corn ethanol, revenue of DDGS, revenue of corn oil, fixed cost of corn purchase, fixed cost of warehouse, fixed raw material inventory cost, variable raw material inventory cost, flexible capacity cost for biorefinery, fixed cost of biorefinery purchase, ethanol inventory variable cost, transportation cost of raw material, transportation cost of pre-treated feedstock, transportation cost of ethanol to demand zones, other supply chain fixed costs, variables costs, and other capital costs.

\section{Profit for cellulosic supply chain}

The objective for the cellulosic ethanol supply chain is profit maximization (i.e. revenue - cost) and it is provided as:

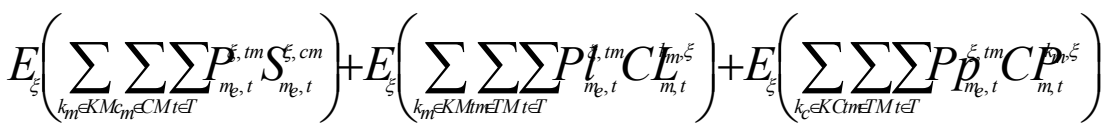

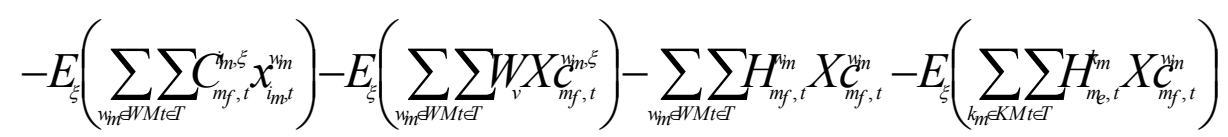

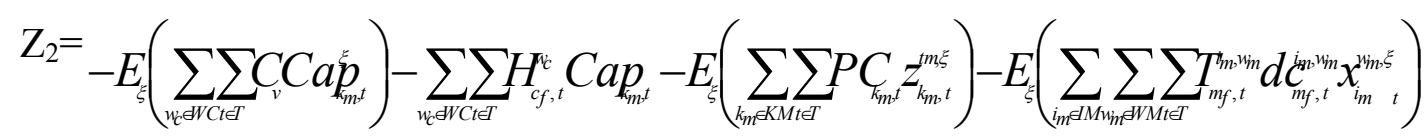

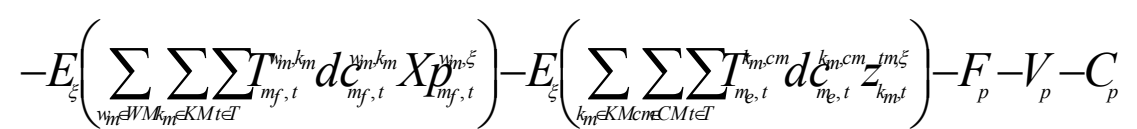

The different components of the equations are for the cellulosic ethanol supply chain and are respectively explained as follows: revenue of cellulosic ethanol, revenue of lignin, revenue of protein, fixed cost of warehouse, fixed raw material inventory cost, variable raw material inventory cost, flexible capacity cost for biorefinery, fixed cost of biorefinery purchase, ethanol inventory variable cost of biorefineries transportation cost of raw material, transportation cost of pre-treated feedstock, transportation cost of ethanol to demand zones, other supply chain fixed costs, variables costs, and other capital costs. The objective function therefore maximizes $\mathrm{Z1}+\mathrm{Z} 2$ subject to the corn and cellulosic ethanol supply chain constraints.

The following is a brief description of the supply chain constraints employed in our model: 


\section{Corn ethanol supply chain constraints}

(3) The total amount of corn feedstock supplied from the sources to the warehouse should not exceed the amount available at the sources. (4) At any given period, the amount of corn ethanol sold to each trade market should not exceed the market demand. (5) At any given period, the amount of cellulosic ethanol sold should not exceed the amount produced. (6) The total corn and cellulosic production should not exceed the total demand. (7) Total demand from corn and cellulosic should be equal to total demand based on the RFS mandate. (8) The amount of corn ethanol produced should not exceed the corn ethanol plant production capacity. (9) Capacity limits for both the corn based warehouse and corn based bio refinery should not exceed production. (10) Variable capacity limits for both the corn based warehouse and corn based bio refinery. (11) The amount of corn ethanol produced is proportional to the feedstock conversion rate. (12) The amount of pretreated corn feedstock transported to corn bio refinery plants should not exceed the plant capacity. (13) Quantity of DDGS produced is proportional to the consumption rate of the corn feedstock. (14) Quantity of corn feedstock pre-treated is consumption of the corn feedstock. (15) The amount of corn oil produced is proportional to the rate of conversion of the feedstock. (16) The amount of corn feedstock pretreated and transported to corn biorefinery plants is less or equal to the plant capacity.

\section{Cellulosic ethanol supply chain constraints}

(17) The total amount of cellulosic feedstock supplied from the source to the warehouse should be less than or equal to the amount available at the sources. (18) The amount of cellulosic ethanol sold to the market cannot be more than the market demand at a given time period. (19) The amount of cellulosic ethanol produced should be at least as much as the amount sold in any given time period. (20) The total production of ethanol from corn and cellulosic feedstock should be equal to the total ethanol demand. (21) The total production from corn and cellulosic demand should be equal to total demand. (22) The amount of cellulosic ethanol produced should be always less than the cellulosic plant production capacity. (23) The capacity of cellulosic based warehouse. (24) The capacity of cellulosic based biorefinery. (25) The variable cost of cellulosic based warehouse. (26) The variable capacity of cellulosic based biorefinery. (27) The amount of cellulosic ethanol produced is proportional to the rate of conversion in the cellulosic ethanol production. (28) The amount of cellulosic feedstock pretreated transported to biorefinery plants is less or equal to the plant capacity. (29) The amount of lignin produced is proportional to the rate of consumption of the cellulosic feedstock. (30) The amount of protein produced is proportional to the rate of consumption of the cellulosic feedstock.

\subsection{Mathematical Model with Hedging Strategy}

This section proposes a mathematical model with hedging strategy. Again, the assumption here is that the decision variables such as the amount of corn feedstock purchased, and the amount of ethanol sold are decided through taking a futures position in the market.. Therefore, equation substitutions are made for the revenue obtained by selling corn ethanol $c_{e}$ produced at plant $k_{c}$ and soldat the trade market $t m$ for time period $t$ during hedging. The rest of the equations are as follows:

\section{The profit for corn ethanol supply chain with hedging is given by}

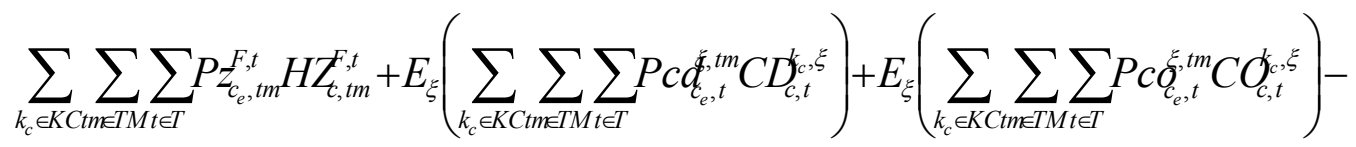

$$
\begin{aligned}
& \sum_{w_{c} \in W C t \in T} \sum_{c_{f}, t m}^{F, t} X_{c_{f}, t m}^{F, t}-c p o{\underset{c}{c_{f}}, t m}_{X^{, t}}^{F}-\sum_{k_{c} \in K C_{c_{m} \in C M}} \sum_{t \in T} T_{c_{e}, t}^{k_{c}, c m} d c_{c_{e}, t}^{k_{c}, t m} H Z_{c_{e}, t m}^{F, t}
\end{aligned}
$$

We assume the revenue for lignin, protein, DDGS, and corn oil are same since there is no liquidly for their markets: the same equations are shown below. The different components of the equations are for the corn ethanol supply chain and are respectively explained as follows: revenue of corn ethanol, revenue of DDGS, revenue of corn oil, corn feedstock purchased cost, cost incurred in taking a futures position, transportation cost of ethanol to demand zones, other supply chain fixed costs, variables costs, and other capital costs.

The revenue from the cellulosic ethanol supply chain is also given by 


$$
\begin{aligned}
& \sum_{k_{m} \in K M c_{m} \in C M} \sum_{t \in T} P z_{m_{e}, t m}^{F, t} H Z_{m, t m}^{F, t}+E_{\xi}\left(\sum_{k_{m} \in K M t m \in T M} \sum_{t \in T} P P_{m_{e}, t}^{\xi, t m} C L_{m, t}^{k_{m}, \xi}\right)+E_{\xi}\left(\sum_{k_{c} \in K C t m \in T M} \sum_{t \in T} P p_{m_{e}, t}^{\xi, t m} C P_{m, t}^{k_{m}, \xi}\right) \\
& -\sum_{w_{m} \in W M} \sum_{t \in T} P X_{m_{f}, c m}^{S, t} X_{m_{f}, c m}^{S, t}-\sum_{k_{m} \in K M} \sum_{t \in T} T_{m_{e}, t}^{k_{m}, c m} d c_{m_{e}, t}^{k_{m}, c m} H Z_{m_{e}, c m}^{,, t}
\end{aligned}
$$

The different components of the equations are for the corn ethanol supply chain and are respectively explained as follows: revenue of corn ethanol, revenue of lignin, revenue of protein, corn feedstock purchased cost, cost incurred in taking a futures position, transportation cost of ethanol to demand zones, other supply chain fixed costs, variables costs, and other capital costs.

Further constraints for the hedging model are provided as follows:

\section{Constraints for hedging in corn}

(33) The corn feedstock supplied from the source to the warehouse should be less than or equal to the amount available at the source. (34) The amount of corn ethanol sold to each trade market cannot be more than the market demand at a given time period. (35) The corn ethanol produced should be at least as much as the amount sold in any given time period. (36) The corn ethanol produced should be always less than the ethanol plant production capacity. (37) The total production of ethanol from corn and cellulosic feedstock for the hedging case should be equal to the total demand. (38) The amount of corn ethanol produced is proportional to the rate of conversion of the feedstock.

\section{Constraints for hedging in cellulosic}

(39) The cellulosic feedstock supplied from the source to the warehouse should be less than or equal to the amount available at the source. (40) The amount of cellulosic ethanol sold to the market cannot be more than the market demand at a given time period. (41) The cellulosic ethanol produced should be at least as much as the amount sold in any given time period. (42) The cellulosic ethanol produced should be always less than the cellulosic plant production capacity. (44) The amount of cellulosic ethanol produced is proportional to the rate of conversion in the products production.

\section{General hedging constraints}

$$
\begin{aligned}
& X_{c_{f}, t m}^{F, t} \leq M Y_{\text {corn_fut }}(\xi) \forall F, \forall t m, \forall c_{f}, \forall \xi, \forall t \\
& X_{c_{f}, t m}^{F, t} \leq M Y_{\text {corn_spot }}(\xi) \forall F, \forall t m, \forall c_{f}, \forall \xi, \forall t \\
& Y_{\text {corn_spot }}(\xi)+Y_{\text {corn_fut }}(\xi)=1 \forall \xi \\
& Y_{\text {cell_spot }}(\xi)+Y_{\text {cell_ffut }}(\xi)=1 \text {, but } Y_{\text {cell_fut }}(\xi)=0 \quad \forall \xi \\
& X_{m_{f}, c m}^{S, t} \leq M Y_{\text {cell_spot }}(\xi) \forall S, \forall c m, \forall m_{f}, \forall \xi, \forall t \\
& X=X_{m_{f}, c m}^{S, t}+X_{c_{f}, t m}^{F, t} \forall S, \forall c m, \forall F, \forall c_{f}, \forall m_{f}, \forall t \\
& S X_{c_{f}, t m}^{F, t}-\alpha^{*} A v g\left(P X_{c_{f}, t m}^{F, t}\right) \leq Y_{\text {corn_ }_{-} \text {fut }}(\xi) \forall F, \forall t m, \forall c_{f}, \forall \xi, \forall t \\
& \alpha^{*} \operatorname{Avg}\left(P X_{c_{f}, t m}^{F, t}\right)-S X_{c_{f}, t m}^{F, t} \leq Y_{\text {corr_spot }}(\xi) \forall F, \forall t m, \forall c_{f}, \forall \xi, \forall t
\end{aligned}
$$

(45) Is the decision to buy corn, which is based on the futures price. (46) Is the decision to buy corn, which is based on the spot amount and price. (47) Is the binary decision to buy either corn or cellulose, which is stochastic. (48) Is the binary decision to buy either cellulose, which is based on spot. (49) Is the decision to buy cellulose, which is based on the spot amount and price. (50) Is the decision to buy corn and cellulosic feedstock being equal to feedstock amount needed. (51) Is the decision to buy corn, which is based on the futures amount and price. (52) Is the decision to buy corn, which is based on the spot amount and price. 


\subsection{Sustainability Constraints}

This section introduces the constraints for the first part which proposes a mathematical model for the economic objective function maximization. The objective function seeks to maximize the total sustainable benefits of the supply chain which includes economic, environmental, and social benefits. The economic benefit comprises selling ethanol and its related by-products and the costs such as raw materials purchase and transportation. Environmental sustainability benefits involve emission trading, which consists of buying and selling GHG permits. Finally, the social sustainability benefits consider corporate social responsibility projects that are invested in by the biorefinery plants. The objective function is subject to GHG emission and corporate social responsibility constraints. These constraints explanations can be deduced from the appendix.

\section{GHG emission constraints}

Eq. (53) GHG emission for the entire supply chain

$$
\begin{aligned}
& \sum_{i_{m} \in I M} \sum_{w_{m} \in W M} \sum_{t \in T} G H G_{c o 1}\left(T_{m_{f}, t}^{i_{m}, w_{m}} d c_{m_{f}, t}^{i_{m}, w_{m}} x_{i_{m}}^{w_{m, \xi}}\right)+\sum_{w_{c} \in W C} \sum_{k_{c} \in K C} \sum_{t \in T} G H G_{c o 2}\left(T_{c_{f}, t}^{w_{c}, k_{c}} d c_{c_{f}, t}^{w_{c}, k_{c}} X p_{c_{f}, t}^{w_{c}, \xi}\right) \\
& +\sum_{t=1}^{T} \sum_{i=1}^{I} \sum_{k=1}^{K} G H G_{c o 3} c_{i, k}^{t} z_{k_{m}, t}^{c m, \xi}+\sum_{k_{m} \in K M} \sum_{c m \in C M} \sum_{t \in T} G H G_{c o 4}\left(T_{m_{e}, t}^{k_{m}, c m} d c_{m_{e}, t}^{k_{m}, c m} z_{k_{m}, t}^{c m, \xi}\right)+ \\
& \sum_{k_{m} \in K M} \sum_{c m \in C M} \sum_{t \in T} G H G_{c o 5}\left(p_{m_{e}, t}^{k_{m}, c m} z_{k_{m}, t}^{c m, \xi}\right)+\sum_{k_{m} \in K M} \sum_{c m \in C M} \sum_{t \in T} G H G_{c o 6}\left(w_{m_{e}, t}^{k_{m}, c m} z_{k_{m}, t}^{c m, \xi}\right)=\operatorname{Carbon}(\xi) \\
& \forall k_{m}, \forall m_{e}, \forall w_{c}, \forall \xi, \forall c_{f}, \forall t
\end{aligned}
$$

Eq. (54) GHG emission for the entire supply chain

$$
\operatorname{Carbon}(\xi)+\operatorname{Excess}(\xi)=\mathrm{TTE}+\operatorname{Extra}(\xi) \forall \xi
$$

Eq. (55) GHG constraint for excess emission

$$
\operatorname{Carbon}(\xi)+\operatorname{Excess}(\xi) \geq \text { TTE } \forall \xi
$$

Eq. (56) GHG constraint for extra emission

$$
\operatorname{Carbon}(\xi)-\operatorname{Extra}(\xi) \leq \mathrm{TTE} \forall \xi
$$

\section{Corporate social responsibility constraints}

Eq. (57) constraints for corporate social responsibility investment

$$
\sum_{t b \in T B} \sum_{q \in Q} C g_{t b, q} X C S R_{t b, q} \leq \alpha^{*} Z_{2} \forall t b, \forall q
$$

where $Z_{2}=Z_{1}-\operatorname{CSRrc}$

Eq. (58) constraint for building a biorefinery at any location

$$
Y_{t b, c, q} \leq 1 \quad \forall t b, \forall q, \forall q c
$$

Eq. (59) constraint for sales and amount produced for corn biorefinery

$$
S_{c_{e}, t}^{\xi, t m} \geq z_{k_{c}, t}^{t m, \xi} \forall k_{c}, \forall c_{e}, \forall \xi, \forall t m, \forall t
$$

Eq. (60) constraint for sales and amount produced for cellulosic biorefinery

$$
S_{m_{e}, t}^{\xi, t m} \geq z_{k_{m}, t}^{t m, \xi} \forall k_{m}, \forall m_{e}, \forall \xi, \forall t m, \forall t
$$


Eq. (61) constraint for warehouse installation at a plant

$$
W_{t b c, q}=Y_{t b, c, q} \forall t b, \forall c, \forall q
$$

\section{Solution Technique: Multi-Cut Benders Decomposition}

Multi-cut Benders decomposition (MBD) is applied to solve both models. The MBD algorithm is to add one cut per realization of uncertainty to the master problem in each iteration. This essentially means to add Benders cuts as the number of scenarios added to the master problem in each iteration (You \& Grossmann, 2013). Some advantages in using the MBD algorithm is the improved percentage in the upper and lower bounds. This method is an extension of the Benders decomposition algorithm as discussed in (Kalvelagen, 2003). In order not to have redundancy in equations, a general two-stage stochastic problem is introduced below to make reference to the algorithm easy and for clearer explanation. The two-stage stochastic problem for the MBD algorithm is discussed further. Eq. (62) is the general two-stage stochastic problem, while, eq. (63) and (64) are the master and sub-problem respectively.

\section{Two-stage stochastic problem}

$$
\begin{aligned}
& \text { Max } \quad z=c^{T} x+E_{\zeta}\left[\max q(w)^{T} y(w)\right] \\
& \text { s.t. } \quad \mathrm{Ax} \leq b, \\
& \mathrm{~T}(\mathrm{w}) \mathrm{x}+\mathrm{W}(\mathrm{w})=\mathrm{h}(\mathrm{w}) \\
& \quad \mathrm{x} \geq 0, \mathrm{y}(\mathrm{w}) \geq 0 .
\end{aligned}
$$

\section{Master problem}

$$
\begin{aligned}
& \text { Min } \quad z_{1}=c^{T} x+\sum_{\xi} p_{\xi} \eta_{\xi} \\
& \text { s.t. } \quad \mathrm{Ax}=b, \\
& \eta_{\xi} \geq \pi_{\xi}\left(\mathrm{h}_{\xi} \mathrm{x}+T_{\xi}\right) \forall \xi \\
& \mathrm{x} \geq 0, \mathrm{z}_{\mathrm{j}, \mathrm{k}} \geq 0 .
\end{aligned}
$$

\section{Sub problem}

$$
\begin{aligned}
& \text { Min } \quad z_{2}=d_{\xi}^{T} y_{\xi}(\xi) \\
& \text { s.t. } \quad \mathrm{W}_{\xi} \mathrm{y}_{\xi}(\xi)=\mathrm{h}_{\xi}(\xi)-\mathrm{T}_{\xi} \text { xbar } \\
& \quad \mathrm{x} \geq 0, \mathrm{y}(\xi) \geq 0 \\
& \text { Where } x \text { bar is the optimal solution of } \mathrm{x} \text { in } \\
& \text { the first stage }
\end{aligned}
$$

The Multi-cut Benders algorithm is as follows:

Step 1. Set $l=1 T, \varepsilon, U B=+i n f, L B=-i n f$, where $l$ is the iteration counter, and $U B_{l}=\infty$, that is, upper bound is set to positive infinity, and the lower bound is set to negative infinity, $L B_{l}=-\infty$

Step 2. Generate the scenarios for $N$ samples for the demand and price data. Solve eq. (62) and add $\eta_{\xi} \geq \pi_{\xi}\left(\mathrm{h}_{\xi} \mathrm{x}+T_{\xi}\right)$ which is like a 'hot' start to reach optimality

Step 3. Solve the sub problem, i.e. eq. (64) to obtain the optimal first-stage decisions, i.e. xbar

Step 4. Determine the dual of the sub problem, and represent them by the dual variables, in this case: $\pi_{\xi}$

Step 5. Update the upper bound by setting: $U B_{l+1}=\min \left\{U B_{1}, z_{1}+z_{2}\right\}$, where $z_{l}$ and $z_{2}$ are the objective function value of the master and sub problems respectively

Step 6. Update the lower bound problem by using: $L B_{l+1}=z_{1}+\eta$, where $z_{l}$ is the master problem objective function with cut, $\eta$

Step 7. Add cut to the master problem

Step 8. Proceed to test for the optimal solution with a stopping criteria, otherwise, set the iteration counter to $l=l+1$. The criterion uses a tolerance which is a pre-determined for the stopping criterion

Step 9. Solve the updated master problem and add the probabilities and scenarios to the cut and go back to step 3 . 


\subsection{Hedging Strategies}

As discussed in section 1, hedging strategy is a mechanism commonly used to reduce extreme risk due to price volatilities of commodities or stock (Gurnani \& Tang, 1999; Bazaraa \& Sherali, 1981). The concept of futures gives additional flexibility in trading with commodities to buy or sell a futures contract at a designated strike price (Das, 2011). Futures hedging strategy is proposed in this model for a quarterly-period financial hedging strategy used for hedging against the uncertain corn feedstock and corn ethanol prices. The flow process for the hedging strategy is shown in figure 3.

\subsubsection{Flow Chart of Hedging Strategy}

The flow chart for the proposed hedging strategy is illustrated below.

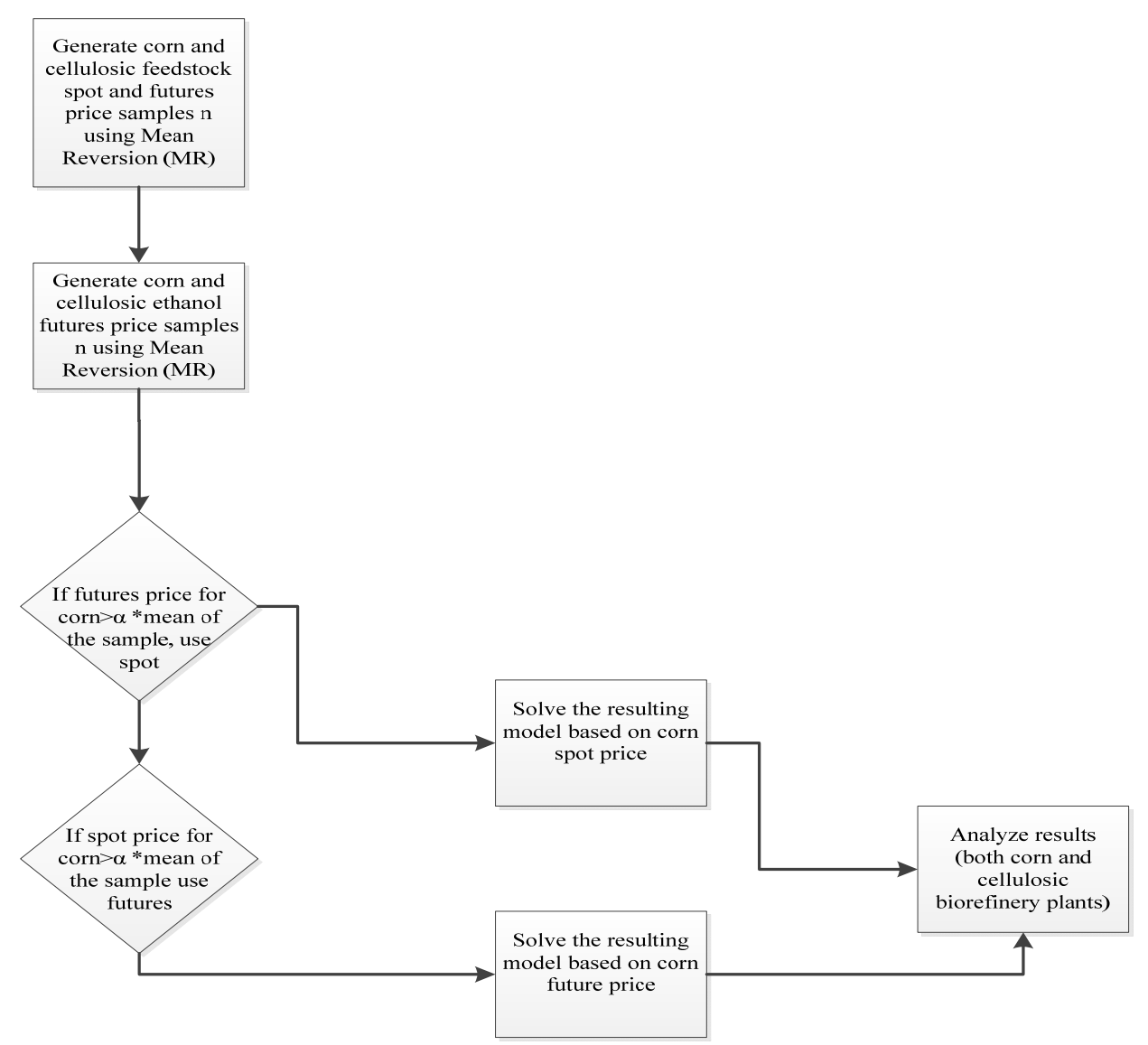

Figure 3. Hedging flow diagram for the strategy used

\subsection{Modeling Price Uncertainty}

Mean reversion (MR) models are widely used in finance. In this paper, mean reversion is used to model the price uncertainties of ethanol and corn feedstock. Mean reversion models are important since they reflect the proper or accepted mechanisms with which the stock market or commodity prices behave (Gallant et al., 1999). The concept is that the high and low prices of a commodity or stock are temporary, and that the stock price will move or shift to the average price over time (Schwartz, 1997). They are widely used to model interest rates, especially for commodities. Another popular name of this model is the Ornstein and Uhlenbeck or 'O-U' process. This is also used for modeling price uncertainties as in Bazaraa et al. (2008). The Ornstein Uhlenbeck process is widely used for modeling a mean reverting process which is given by the formula below:

$$
d s=\lambda(\mu-S) d t+\propto d W_{t}
$$

Where $W_{t}$ is the Brownian Motion, with $\mathrm{dWt} \sim \mathrm{N}(0, \sqrt{d t}), \lambda$ is the speed of mean reversion, $\mu$ is the long run 
mean which the process tends to revert to, and $\sigma$ the measure of the process volatility. Where $d t$ is the change in time. This paper adopts this model by first determining the mean value of the data provided and using it to calibrate the required parameters.

\subsubsection{Calibrating the Price (MR) Parameters}

The reversion rate and mean level can be calculated from the coefficients of a linear fit between the log prices and their first difference scaled by the time interval parameter. Equation (i) can be re-written as $S_{t}-S_{t-1}=\lambda(\mu-S) \Delta t+\sigma d W_{t} \quad \ldots$ (ii). Separating terms and expressing the equation in a linear regression form $y=a+b x+\varepsilon_{t} \ldots$ (iii) and after mathematical manipulation yields the following terms for the reversion rate and mean level respectively: $\lambda=\operatorname{In}(b) / \Delta t \ldots$ (iv) and $\mu=a /(1-b) \ldots(\mathrm{v})$

\subsubsection{Proposed Heuristic Hedging Strategy}

A heuristic method is used to provide a computationally tractable approach to solve the problem. The heuristic method uses the mean reversion model to generate $n$ sample data for both the corn spot and futures prices as discussed in the problem statement. Two different samples are picked to authenticate the model or ensure fairness. Following the discussion on hedging, the next section introduces the modeling of price uncertainties. A sample of the scenario generated in the heuristic method is shown table 1 below.

Table 1. Heuristic strategy sample scenario

\begin{tabular}{lllllll}
\hline Scenario & Spot_corn & Future_corn & Mean & Y_spot & Y_fut & PRICE \\
\hline 1 & 7.459788464 & 7.041125708 & 7.3512 & 0 & 1 & 7.0411257 \\
2 & 6.857595768 & 6.845238288 & 7.3512 & 0 & 1 & 6.8452383 \\
3 & 7.40676642 & 7.387176137 & 7.3512 & 0 & 1 & 7.4067664 \\
4 & 7.416234608 & 7.205385202 & 7.3512 & 0 & 1 & 7.2053852 \\
5 & 7.096484325 & 6.919995895 & 7.3512 & 0 & 1 & 6.9199959 \\
6 & 7.397894038 & 7.406470446 & 7.3512 & 1 & 0 & 7.397894 \\
7 & 7.3517407 & 6.812084249 & 7.3512 & 0 & 1 & 6.8120842 \\
8 & 6.991755743 & 7.446363526 & 7.3512 & 1 & 0 & 6.9917557 \\
9 & 6.812084249 & 6.7840901 & 7.3512 & 0 & 1 & 6.7840901 \\
10 & 6.996535871 & 6.982476173 & 7.3512 & 0 & 1 & 6.9824762 \\
\hline
\end{tabular}

\subsection{Input Parameters}

The following input parameters are provided in Tables 2 and 3. Values of other key input parameters are referenced from Zhang et al. (2013). Mean reversion is used for the price uncertainty modeling. Corn and cellulosic feedstock prices are generated for the generalized number of scenarios used in the study. Similar analysis is conducted for the ethanol. Both corn and cellulosic ethanol are also generated using the mean reversion prices. Non-hedging uses the spot price for the decision making while hedging for both feedstock and end-products is based on the heuristic method developed. The detailed heuristic method purchases cellulosic feedstock at a spot price. The heuristic method uses the mean reversion model to generate sample data for both the corn spot and futures prices. Similarly, corn and cellulosic ethanol analysis are conducted using the method discussed. A method of buying corn feedstock using the spot price is used if futures price is greater than the 1.05 times the mean of the sample price generated. Meanwhile, similar heuristic method is adopted for the futures. It should be noted that the 5\% threshold used for the analysis is to conform to the value at risk, which is $5 \%$ of the downside risk. 
Table 2. Corn BSC and input data

\begin{tabular}{lll}
\hline Parameters & Values & Units \\
\hline Cost of corn feedstock & MR $(6.75,0.095)$ & $\$$ (dollars)/bushel \\
Price of corn ethanol & MR $(2.75,0.095)$ & $\$$ (dollars)/gal \\
Corn ethanol demand & Based on county/month & gallons \\
Capacity of corn biorefinery plant 1 & $120,000,000$ & Gallons/yr \\
Capacity of corn biorefinery plant 2 & $120,000,000$ & Gallons/yr \\
Unit raw material transportation cost to plants & $0.0718 /$ mile & $\$$ (dollars) \\
Unit end-products transportation cost & $0.0718 /$ mile & $\$$ (dollars) \\
Unit inventory holding cost for raw material & 0.005 & $\$$ (dollars) \\
Unit inventory holding cost for end-product & 0.005 & $\$$ (dollars) \\
Unit penalty cost for unmet demand & 0.000285 & $\$$ (dollars) \\
Unit cost per processing & $1.24 /$ bushel & $\$$ (dollars) \\
\hline
\end{tabular}

Table 3. Cellulosic BSC and input data

\begin{tabular}{lll}
\hline Parameters & Values & Units \\
\hline Cost of cellulosic feedstock & MR $(3.8,0.095)$ & $\$$ (dollars)/ton \\
Price of cellulosic ethanol & MR $(2.75,0.095)$ & $\$$ (dollars)/gal \\
Cellulosic ethanol demand & Based on county/month & gallons \\
Capacity of cellulosic biorefinery plant 1 & $120,000,000$ & Gallons $/ \mathrm{yr}$ \\
Capacity of cellulosic biorefinery plant 2 & $120,000,000$ & Gallons $/ \mathrm{yr}$ \\
Unit raw material transportation cost to plants & $0.158 / \mathrm{mile}$ & $\$$ (dollars) \\
Unit end-products transportation cost & $0.158 / \mathrm{mile}$ & $\$$ (dollars) \\
Unit inventory holding cost for feedstock & 0.0155 & $\$$ (dollars) \\
Unit inventory holding cost for ethanol & 0.15 & $\$$ (dollars) \\
Unit penalty cost for unmet demand & 0.005 & $\$$ (dollars) \\
Unit cost per processing & $1.24 /$ ton & $\$$ (dollars) \\
\hline
\end{tabular}

\section{Case Study}

The case study will examine a RESC renewable energy supply chain (RESC) in the U.S. state of North Dakota (ND). ND has already established corn ethanol biorefinery plants because of the vast nature and availability of corn feedstock (Martin, 1999; Muir et al., 2001). Studies such as (Zhang et al., 2013) show that ND is suitable for the commercial cultivation of cellulosic feedstock such as switchgrass. Raw materials are purchased from four supply sources. Feedstocks are pre-treated at the warehouse, and the pre-treated raw materials transported to the production facility. Four different biofuel refinery facilities convert the raw materials into end-products; two producing corn-based ethanol, and the other two plants for cellulosic-based ethanol. The entire 53 counties in North Dakota are considered as the demand zones. Figure 2 shows the configuration of the study. Analysis was conducted on the historical data of corn and ethanol price and it was found that corn feedstock prices are more volatile as compared to ethanol. A heuristic method which considers buying corn futures when the price of corn at the spot price is greater than $5 \%$ of the futures price is implemented. This means a method of buying corn feedstock using the spot price is exercised if futures price is greater than the 1.05 times the mean of the sample price generated. A heuristic method is subsequently used for the hedging. Therefore, a multi-period consisting of quarterly time horizon is used.

The study considers hedging and non-hedging scenarios for buying and selling feedstock and end-products respectively. Hedging uses futures price which is generated by mean reversion as discussed earlier. Non-hedging generates similar price scenarios using mean reversion but in this case from a different sample. This assumption is used to ensure fairness and also to reflect the real case on the market. In this paper, corn and cellulosic based ethanol are sold to the commodity market using futures, while the feedstock for both corn and cellulosic are bought using futures, and cellulosic is purchased at the spot price. This concept is being implemented because the current method of cash market is proven not to be practical. The supply chain case study is shown in figure 2 . 


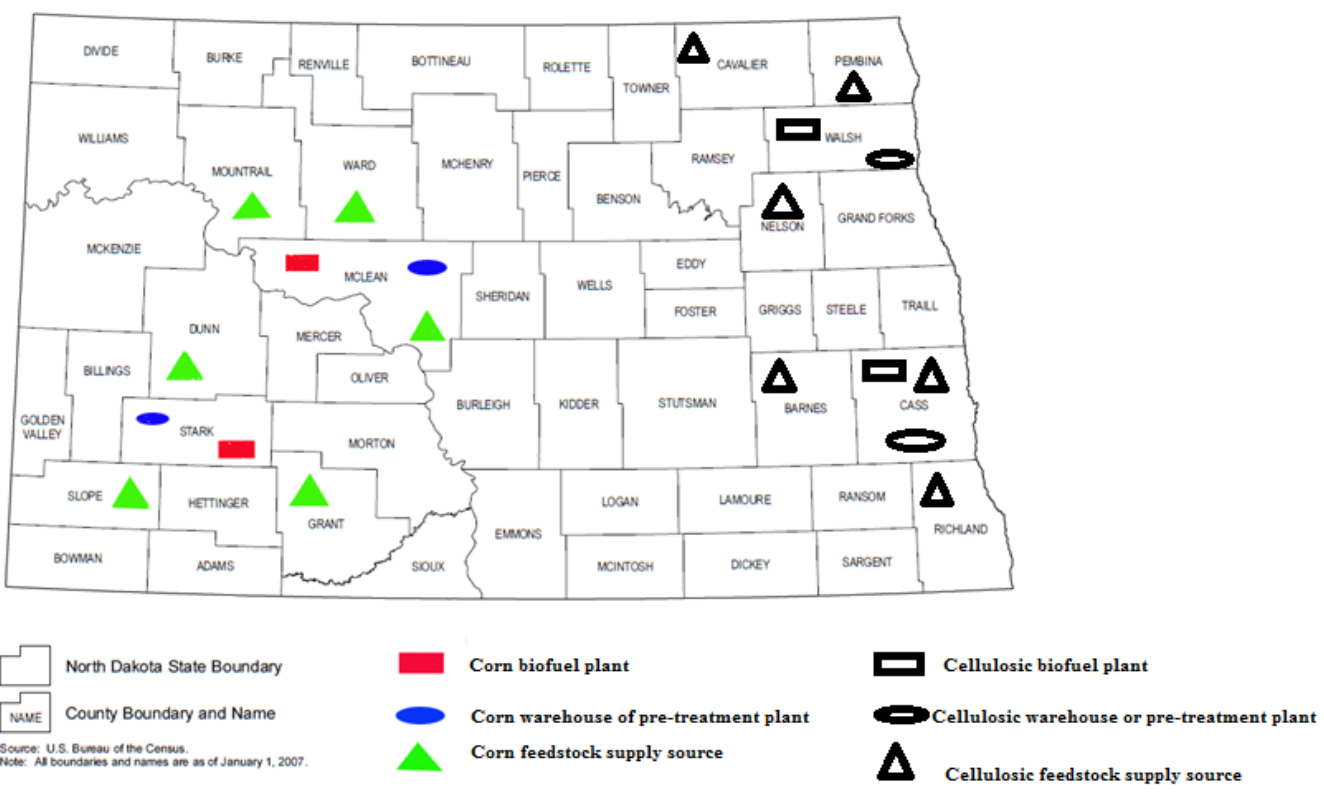

Figure 2. North Dakota Map with counties for case study

\section{Results and Analysis}

The models are solved by the commercial GAMS 26.3.5 version using a CPLEX solver. A Sony Viao of Intel 1.6 Centrino processor of $2.5 \mathrm{GHz}$ is used. The results and subsequent sensitive analyses are presented in the next section. The results summary is shown in Table 4. Mean profits represent the entire expected profit realization for the scenarios adopted. The variance and standard deviation for these scenarios are also calculated. The respective hedging diagrams are shown.

Table 4. Results summary of profit

\begin{tabular}{llll}
\hline Model & Mean & Variance & STD \\
\hline Hedging & $1.321 \mathrm{E}+08$ & $0.832 \mathrm{E}+5$ & 912.2456661 \\
Non-hedging & $1.283 \mathrm{E}+08$ & $1.379 \mathrm{E}+6$ & 1186.776531 \\
\hline
\end{tabular}

The analyses in Figure 4 show the profit and risk curves for hedging and non-hedging. From the results, non-hedging profits are low for higher probabilities or risks as compared to hedging. This means hedging gives better profit realizations at low risks compared to non-hedging. A typical example is the hedged profit margin of $\$ 1.255 \mathrm{E} 8$. This value has a risk of approximately 0.25 for non-hedging as compared to a risk of 0.00 for hedging. The opposite holds for higher values. The non-hedged profit has a risk factor of approximately 0.99 for a profit value of $\$ 1.386 \mathrm{E} 8$, as compared to the hedged case which has the same profit for a risk of 0.99 or approximately 1 . This analysis is in line with the literature which concludes that hedging advantages are realized at low profit values as compared to high profit values. In this instance the decision maker will be circumspect in taking a hedge position or not for a particular profit realization. Furthermore, at a profit of $\$ 1.385 \mathrm{E} 8$, the risk of hedging and non-hedging are the same. This means irrespective of the position taken, the ethanol producer will make that amount of profit, meaning it is better not to hedge since hedging might incur some cost, especially if futures is being used. Figure 4 further provides some managerial insights that are concluded in this analysis. That is hedging is a mechanism that can reduce the exposure to risk, but does not mean higher profits will be realized anytime hedging is used. The conclusion that can be drawn from this section is that, hedging is good for smaller profits, but not necessarily larger profits, since compensation will be paid in terms of higher variance at higher profit values. 


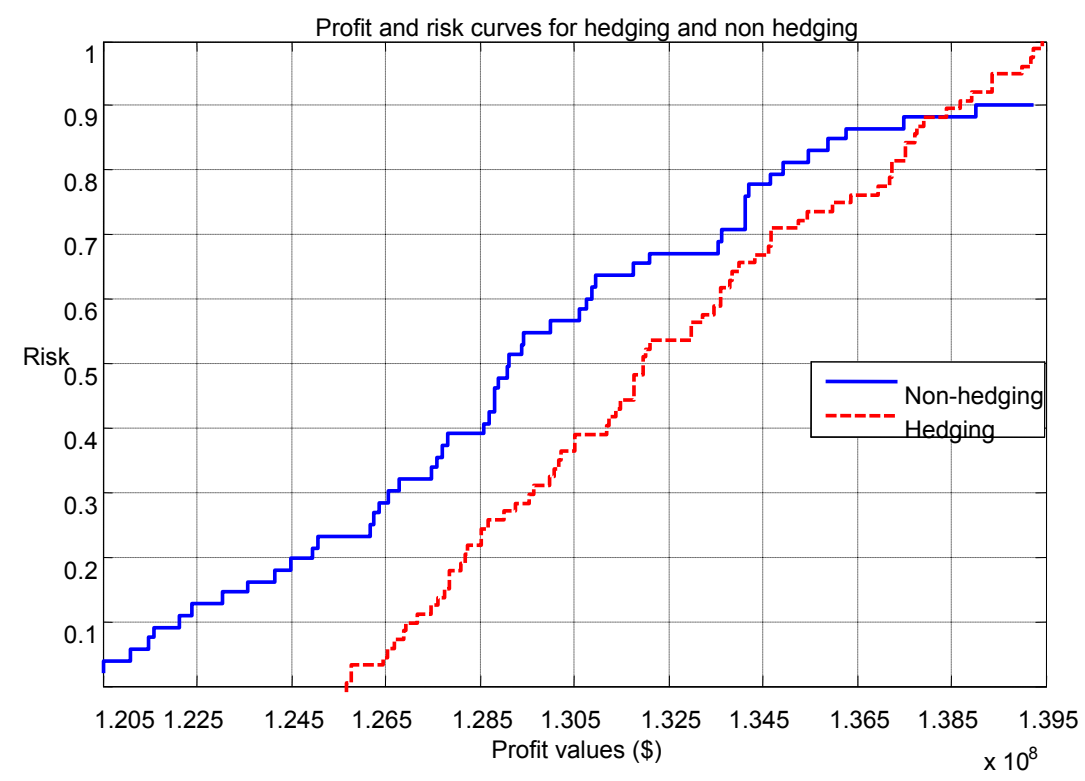

Figure 4. Risk curves comparison for profit with and without hedging

\subsection{The Impact of Raw Materials Cost on Profit}

Since there are two main types of biomass feedstock involved, further analyses are conducted to determine the impact of raw materials cost changes on the profit margin in the supply chain. Currently, the cost of biomass for cellulosic is cheaper as compared to corn feedstock. From the analyses performed, long term cost of biomass from cellulosic will be beneficial only if there are no changes in technology for ethanol production, pre-treatment plants, and other factors. From the bar charts, an approximate increase in the cost of corn will impact the profit more than that of cellulosic. One of the reasons is that corn is traded as a commodity and has several impactors that could affect its price such as economic, political, and weather. Figure 5 therefore represents the profit distribution when the costs of the cellulosic and corn feedstocks are decreased by $15 \%$ in both the hedging and non-hedging scenarios. It is observed that there is an approximately $1.37 \%$ and $3.97 \%$ increase for non-hedging and hedging profits respectively when these changes are made. Similar analyses are conducted for increment in raw material costs.

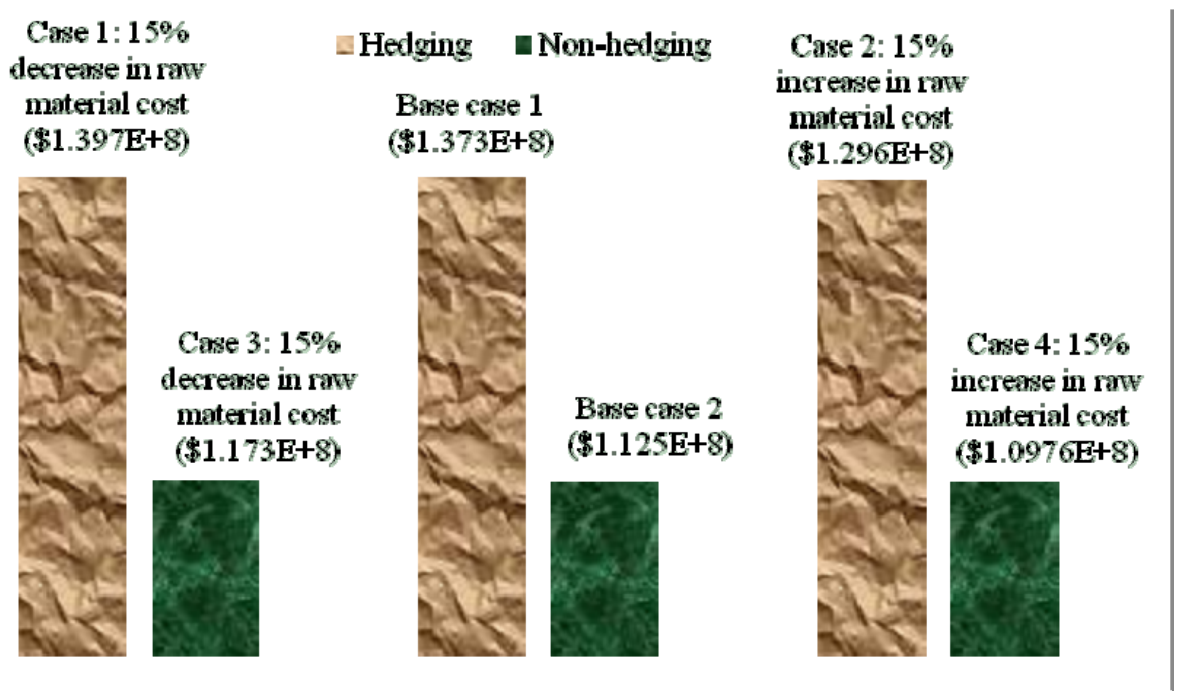

Figure 5. Case comparison for feedstock changes in non-hedging 


\subsection{Profit Contributions from All Products}

This analysis looks at the various contributions of the output products in making up the profit. Two main products are identified as the end-output, which are cellulosic and corn ethanol. There are four by-products, namely lignin and protein (grass left over) from cellulosic feedstock and corn oil and DDGS from corn respectively. The analyses are shown in Figures 6 and 7. The profit analyses are discussed as follows:

1) Hedging: The highest contribution is from corn and cellulosic ethanol which is $95.36 \%$, followed by the by-products, which contribute about $3.73 \%$. Ethanol is basically the mainly used product, followed by the by-products after production of the corn and cellulosic ethanol, which can be used for animal feed such as DDGS and for energy production, such as lignin.

2) Non-hedging: Similarly, another analysis is conducted for the case with other analyses for the corn and cellulosic case without hedging. The highest contribution is from corn and cellulosic ethanol which is $96.57 \%$, and then the by-products, which contribute about $3.37 \%$.

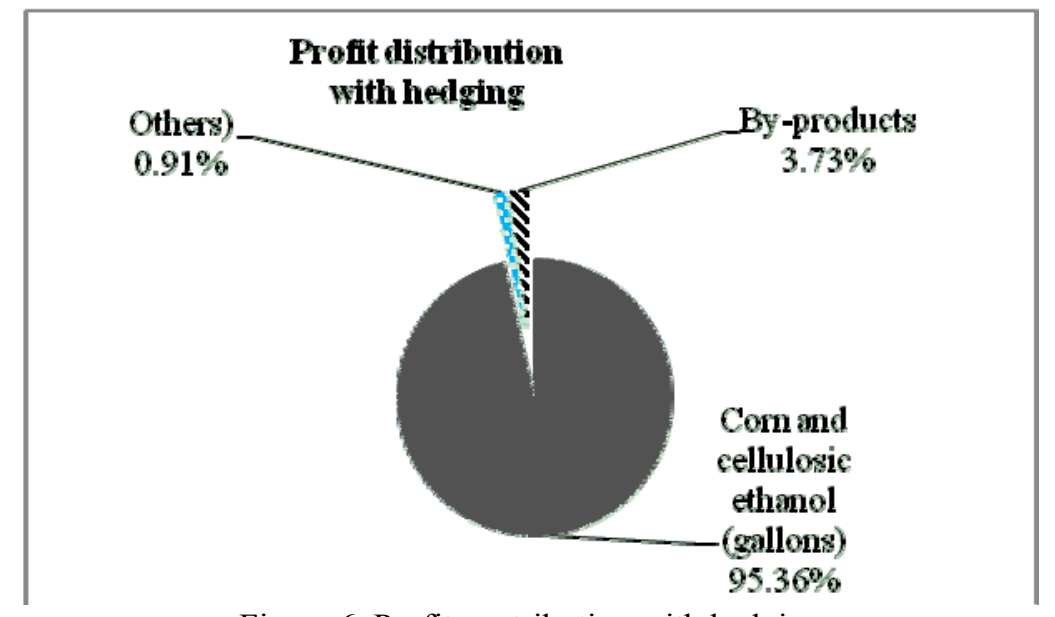

Figure 6. Profit contribution with hedging

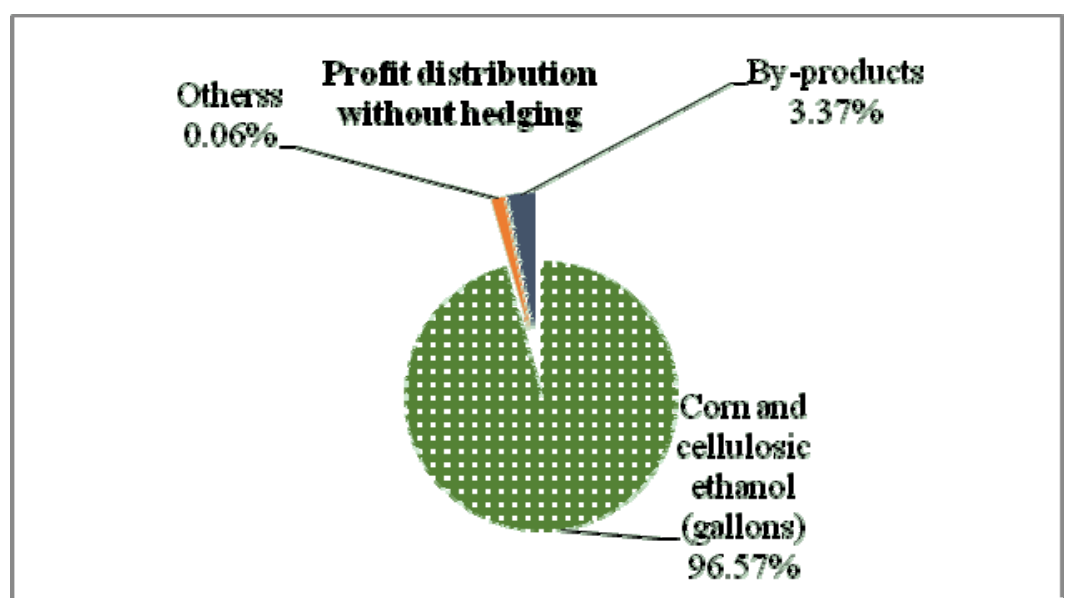

Figure 7. Profit contribution with no hedging

\subsection{Results for Economic, Social and Environmental Sustainability}

In this section, economic, social and environmental sustainability are compared. This is motivated by the increasing impacts of economic activities on social and environmental structures. It is found that when economic sustainability increases, the social sustainability decreases as a result of the threshold of profit margin. Similarly, as economic sustainability increases, environmental sustainability increases until a point where the biorefinery plant reaches maximum capacity and then environmental effect remains unchanged. Sustainability analyses for economic versus social and economic versus environmental are illustrated in Figures 8 and 9. Detailed analyses of 
economic versus social and economic versus environmental are explained below.

Table 5. Economic analysis

\begin{tabular}{lllllll}
\hline Benefit & Units & $\begin{array}{l}\text { CSRf } \\
\text { decrease 2 } \\
(20 \%)\end{array}$ & $\begin{array}{l}\text { CSRf } \\
\text { decrease 1 } \\
(10 \%)\end{array}$ & $\begin{array}{l}\text { Base } \\
\text { case }(0)\end{array}$ & $\begin{array}{l}\text { CSRf } \\
\text { increase } \\
(10 \%)\end{array}$ & $\begin{array}{l}\text { CSRf } \\
\text { Increase 2 } \\
(20 \%)\end{array}$ \\
\hline Economic & $\$$ & $7.601 \mathrm{E}+7$ & $7.60 \mathrm{E}+7$ & $7.598 \mathrm{E}+7$ & $7.597 \mathrm{E}+7$ & $7.59 \mathrm{E}+7$ \\
\hline
\end{tabular}

Note. CSR means corporate social responsibility.

\subsection{Sensitivity Analysis for Economic Versus Social Sustainability}

As discussed previously, the economic benefit reduces as the corporate social responsibility increases until the threshold for the investment of corporate social responsibility, that is $\$ 2.659 \mathrm{E} 6$ is reached. Accordingly, an investment of $\$ 2.659 \mathrm{E} 6$ results in an economic net benefit decrease of $\$ 7.596 \mathrm{E} 7$. This means if further increase in social benefit is needed, then a strategic decision would have to be made. In this case, an increase in profit while maintaining the same social benefit will mean increasing biorefinery capacity as well as high demand realization. Also, a decision at an economic benefit of $\$ 7.5967 \mathrm{E} 7$, corresponds to a corporate social responsibility benefit of $\$ 2.6591 \mathrm{E} 6$, as compared to an economic benefit of $\$ 7.5966 \mathrm{E} 7$ with a corporate social responsibility benefit of $\$ 2.6593 \mathrm{E} 6$. This explains that a biorefinery investment of \$2.6593E6 for a corporate social responsibility is feasible for an economic value of \$7.5966E7. Meanwhile, the net economic benefit of \$7.5966E7 means sustainable project limit is reached. Similarly, the results also indicate the location for the biorefinery will not be affected if the minimum economic benefit is to remain approximately $\$ 7.5966 \mathrm{E}$. The social aspect of sustainability is provided as an index based on the IMPLAN model. This is assumed as $3.5 \%$ of the economic benefit and it is dependent on a threshold based on the level of investment the company decides. Threshold determination is a strategic level investment, which can be attributed to production, demand, sales, plant location, and other factors.

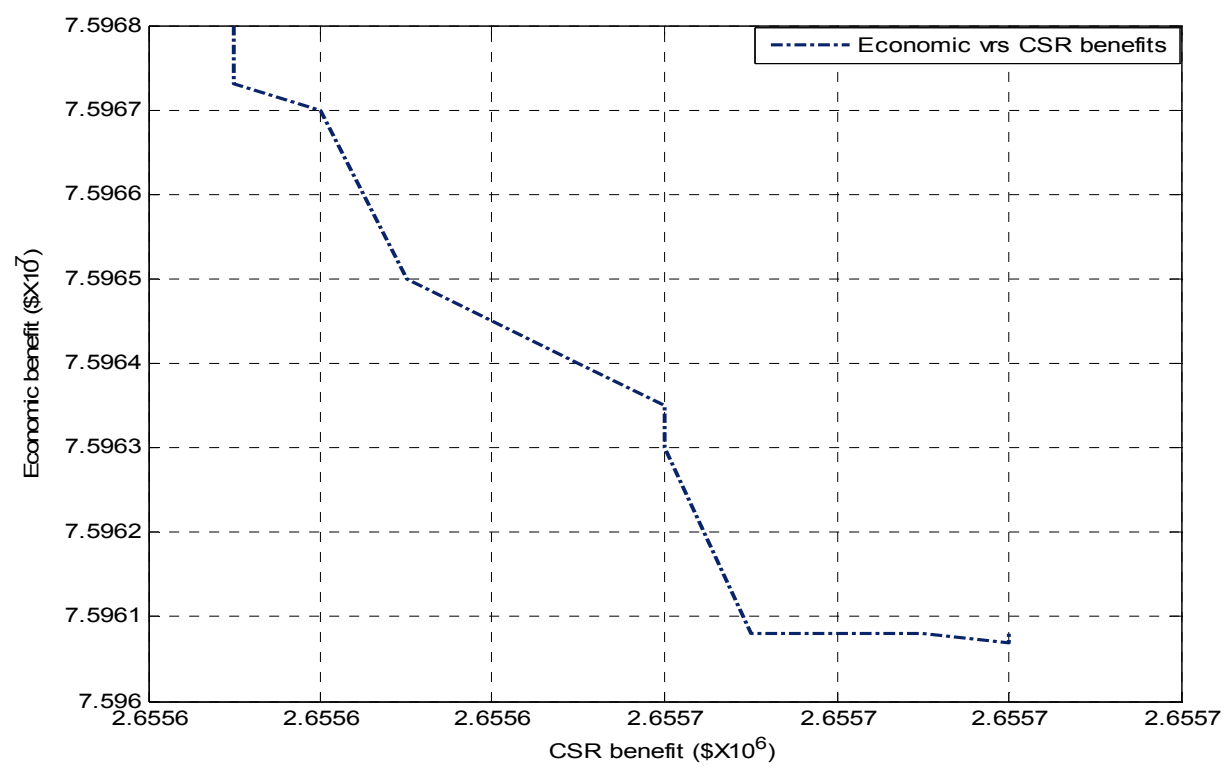

Figure 8. Economic versus social sustainability comparison

\subsection{Sensitivity Analysis for Economic Versus Environmental Sustainability}

Further analysis is conducted for the GHG emission and economic benefit. The results indicate that after carbon emissions of $0.155 \mathrm{E} 8 \mathrm{~kg} \mathrm{C} 02$ equivalent, the maximum economic benefit that can be achieved is around \$7.5967E7 as illustrated in Figure 9. This means further production can result in more emission, but the limit on the profit maximization or economic benefit will have to be set at a different target since increasing profit margin 
will continue until maximum biorefinery capacity is reached. Expanding capacity for more production should also be compensated for more profit margins if there is unlimited demand, which is not practical in most cases since demand has limitation based on the capacity to produce.

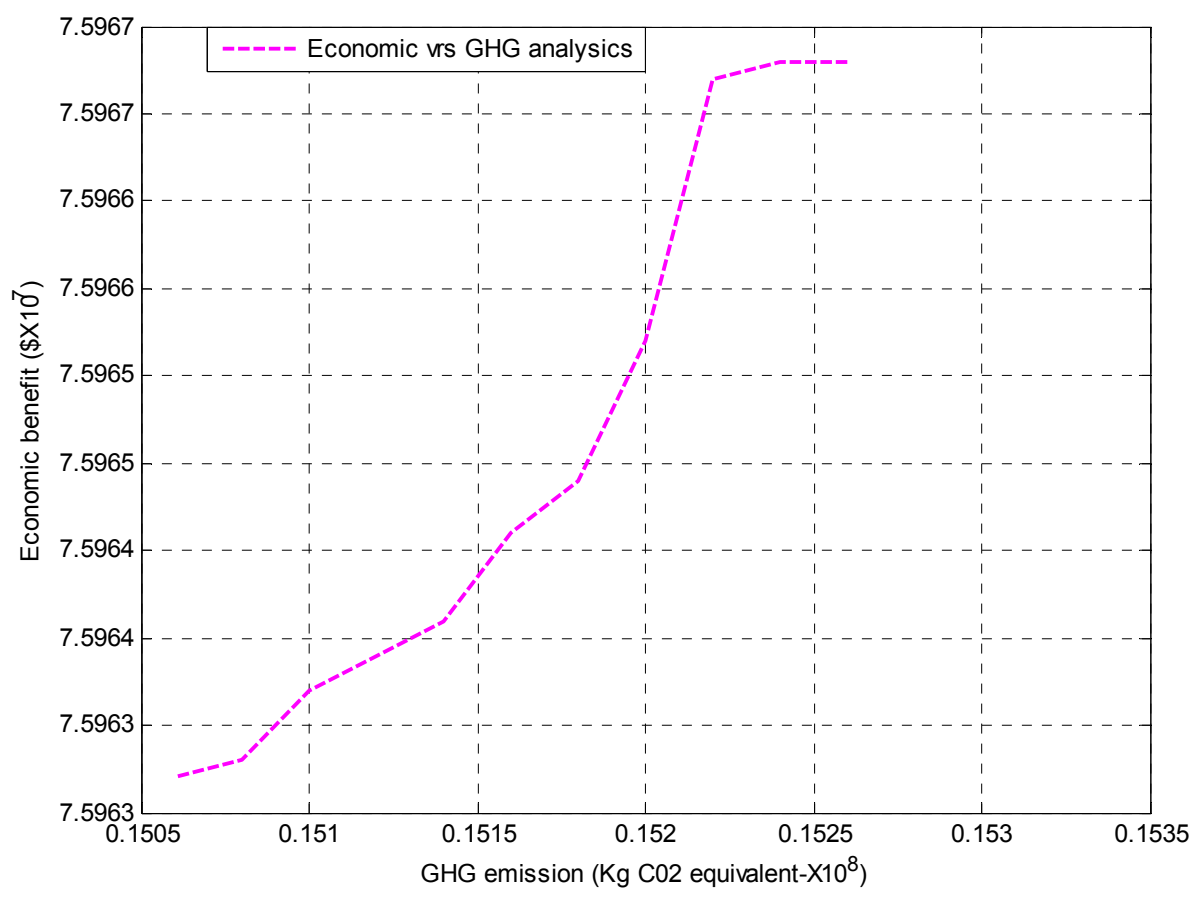

Figure 9. Economic versus environmental sustainability comparison

\section{Conclusion and Future Implications}

This paper develops a model that uses hedging strategies in a RESC renewable energy supply chain (RESC) setting. The hedging method considers the futures and spot prices of corn and cellulosic feedstocks respectively, while the ethanol end-products are hedged using futures. Non-hedging strategy uses spot prices for the purchase of feedstock and sale of end-products. A two-stage stochastic linear programming method based on the Multi-cut Benders Decomposition Algorithm is used to solve the resulting model. The analyses show differences in profit margins in relation to hedging and non-hedging with the non-hedging being less than the hedging. Also, the profit values for the non-hedging at lower profits are observed to be more risky as compared to the profit values of the hedged decisions.

Incorporating logistical uncertainties are crucial since costly supply chain requires various forms of interventions from the main players within the supply chain and other agencies such as government. Integrating logistics within the supply chain have seen significant contributions from major literature citations. In the future, a temporal stochastic optimization model will be developed and logistical strategies such as transit times will be considered. This model will provide the added flexibility of choosing the best shipment destination based on the prices that are available at these shipments locations.

Also, sensitivity analyses based on GHG emission and the economic benefits are conducted as well social and economic benefits. The results conclude that increasing corporate social responsibility will decrease economic benefits unless there is a threshold for corporate social responsibility. Additionally, the more the GHG emission, the more the economic benefit till plant capacity to produce the sale amount of ethanol is met. Further sensitivity analyses are conducted to determine the relationships between ethanol and corn price correlation by using copula. Finally, copula relationship that measures the dependence structure is provided for social versus economic sustainability, and environment versus economic sustainability. The consideration of social and environmental sustainability is one area being explored for future research.

Additionally, using real data and comparing it to the analysis conducted in this research will be a good future direction. Real time data or historical data from sources like Bloomberg and DTN will give added value to the 
novelty of the research and provide a better management insight. Another consideration is using multi-period and multi-stage which indicates a better realization of the actual problem. Multi-period models provide better visibility in terms of inventory models and demand realizations. As inventory control becomes more visible, a daily, weekly, or monthly review of inventory will yield better profits. Finally, additional uncertainties such as conversion rate might influence the optimal hedging strategies that will be used. Combination of hedging strategies such as future, options, and futures options will be a good research direction.

\section{References}

Ahuja, R. K., Magnanti, T. L., \& Orlin, J. B. (1993). Network Flows: Theory, Algorithms and Applications. New Jersey: Prentice Hall.

Arnold, J., \& Minner, S. (2010). Financial and operational instruments for commodity procurement in quantity Competition. International Journal of Production Economics, 131, 96-106. http://dx.doi.org/10.1016/j.ijpe.2010.02.007

Bazaraa, M. S., \& Sherali, H. D. (1981). On the choice of step sizes in subgradient optimization. European Journal of Operational Research, 4, 380-388. http://dx.doi.org/10.1016/0377-2217(81)90096-5

Bazaraa, M. S., Jarvis, J. J., \& Sherali, H. D. (2008). Linear Programming and Network Flows. India: Wiley.

Bessembinder, H., Coughenour, J. F., Seguin, P. J., \& Smoller, M. N. (1995). Mean reversion in equilibrium asset prices: evidence from the futures term structure. The Journal of Finance, 50, 361-375.

Bish, E. K., \& Suwandechochai, R. (2010). Optimal capacity for substitutable products under operational postponement. European Journal of Operational Research, 207(2), 775-783. http://dx.doi.org/10.1016/j.ejor.2010.06.010

Das, K. (2011). Integrating effective flexibility measures into a strategic supply chain planning model. European Journal of Operational Research, 211, 170-183. http://dx.doi.org/10.1016/j.ejor.2010.12.006

Gallant, A. R., Hsu, C. T., \& Tauchen, G. (1999). Using daily range data to calibrate volatility diffusions and extract the forward integrated variance. The Review of Economics and Statistics, 8, 617-631. http://dx.doi.org10.1162/003465399558481

Gupta, A., \& Maranas, C. D. (2003). Managing demand uncertainty in supply chain planning. Computers and Chemical Engineering, 27, 1219-1227. http://dx.doi.org/10.1016/S0098-1354(03)00048-6

Gupta, A., \& Maranas, C. D. (2010). Market-Based pollution abatement strategies: risk management using emission Option contracts. Industrial and Engineering Chemistry Research, 42, 802-810. http://dx.doi.org/10.1021/ie020467d

Gurnani, H., \& Tang, C. S. (1999). Optimal ordering decisions with uncertain cost and demand forecast updating. Management Science, 45, 1456-1462. http://dx.doi.org/10.1287/mnsc.45.10.1456

Huchzermeier, A., \& Cohen, M. A. (1996). Valuing operational flexibility under exchange rate risk. Operations Research, 44, 100-113. http://dx.doi.org/10.1287/opre.44.1.100

Inderfurth, K., \& Kelle, P. (2011). Capacity reservation under spot market price uncertainty. International Journal of Production Economics, 133, 272-279. http://dx.doi.org/10.1016/j.ijpe.2010.04.022

Kalvelagen, E. (2003). Branch-and-bound methods for an MINLP model with semi-continuous variables. Retrieved January 23, 2015, from www.amsterdamoptimization.com/pdf/benders.pdf.

Li, H., Ritchken, P., \& Wang, Y. (2009). Option and forward contracting with asymmetric information: valuation issues in supply chains. European Journal of Operational Research, 197, 134-148. http://dx.doi.org/10.1016/j.ejor.2008.06.021

Li, S., Murat, A., \& Huang, W. (2009). Selection of contract suppliers under price and demand uncertainty in a dynamic market. European Journal of Operational Research, 198, 830-847. http://dx.doi.org/10.1016/j.ejor.2008.09.038

Martin, R. K. (1999). Large Scale Linear and Integer Optimization; A Unified Approach. The Netherlands: Kluwer Academic Publishers.

Muir, J. P., Sanderson, M. A., Ocumpaugh, W. R., Jones, R. M., \& Reed, R. L. ( 2001). Biomass production of 'Alamo' switchgrass in response to nitrogen, phosphorus, and row spacing. Agronomy Journal, 93, 896-901. http://dx.doi.org/10.2134/agronj2001.934896x

Schnepf, R., \& Yacobucci, B. D. (2013). Renewable fuel standards: overview and issues. Congressional Research 
Service Report R40155. Retrieved from http://wv.ncseonline.org/nle/crsreports/10Jul/R40155.pdf

Schwartz, E. S. (1997). The stochastic behavior of commodity prices: implications for valuation and hedging. The Journal of Finance, 52, 923-973.

Tang, C., \& Tomlin, B. (2008). The power of flexibility for mitigating supply chain risks. International Journal of Production Economics, 116, 12-27. http://dx.doi.org/10.1016/j.ijpe.2008.07.008

Titodiya, V. (2010). Trading strategies and accounting procedure of derivatives. Retrieved March 10, 2014, from www.scribd.com/doc/39734922/28/Hedging-mechanism

Wu, C. H., \& Chuang, Y. T. (2010). An innovative approach for strategic capacity portfolio planning under Uncertainties. European Journal of Operational Research, 207, 1002-1013. http://dx.doi.org/10.1016/j.ejor.2010.05.015

You, F., \& Grossmann, I. E. (2013). Mulicut Benders Decomposition Algorithm for process supply chain planning under uncertainty. Annals of Operations Research, 210, 191-211. http://dx.doi.org/10.1007/s10479-011-0974-4

Yun, C., Kim, Y., Park, J., \& Park, S. (2009). Optimal procurement and operational planning for risk management of an integrated biorefinery process. Chemical Engineering Research and Design, 87, 1184-1190. http://dx.doi.org/10.1016/j.cherd.2009.02.007

Zhang, J., Osmani, A., Awudu, I., \& Gonela, V. (2013). An integrated optimization model for switchgrass-based bioethanol supply chain. Applied Energy, 102, 13-21.

\section{Appendix A}

\section{Index/Sets:}

$i_{c} \quad$ The index of corn feedstock supply source $i_{c}=1,2 \ldots I_{c}$

$i_{m} \quad$ The index of cellulosic feedstock supply source $i_{m}=1,2 \ldots I_{m}$

$w_{c} \quad$ The index of warehouse for storing corn feedstock $w_{c}=1,2, \ldots I_{c}$

$w_{m} \quad$ The index of warehouse for storing cellulosic feedstock $w_{m}=1,2, \ldots I_{c}$

tm The index of trade market $t m=1,2,3 \ldots T M$ (Futures)

$\mathrm{cm} \quad$ The index of cash market $\mathrm{cm}=1,2,3 \ldots C M$ (Spot)

$k_{c} \quad$ The index of corn biorefinery $k_{c}=1,2,3 \ldots K C$

$k_{m} \quad$ The index of cellulosic biorefinery $k_{m}=1,2,3 \ldots K M$

$c_{f} \quad$ The index of corn feedstock index

$c_{e} \quad$ The index of corn ethanol index

$m_{f} \quad$ The index of cellulosic feedstock index

$m_{e} \quad$ The index of cellulosic ethanol index

$t \quad$ The index of time horizon for the entire period of planning $\mathrm{t}=1,2, \ldots T$

\section{Deterministic parameers}

$P C_{k_{c}, t} \quad$ Production cost of corn ethanol at plant $k_{c}$ in time period $t$

$P M_{k_{m}, t} \quad$ Production cost of cellulosic ethanol at plant $k_{m}$ in time period $t$

$H_{c_{f}, t}^{w_{c}} \quad$ Inventory holding cost for corn feedstock $c_{f}$ at warehouse $w_{c}$ at time period $t$

$H \underset{m_{f}, t}{w_{m}}$ Inventory holding cost for cellulosic feedstock $m_{f}$ at warehouse $\mathcal{W}_{m}$ in time period $t$

$H_{c_{e}, t}^{k_{c} f} \quad$ Pre-treatment or handling cost for corn feedstockat plant $k_{c}$ in time period $t$

$H_{m_{e}, t}^{k_{m}} \quad$ Pre-treatment or handling cost for cellulosic feedstockat plant $k_{c}$ in time period $t$ 
$F_{p} \quad$ Fixed operational cost of the supply chain

$V_{p} \quad$ Variable operational cost of the supply chain

$A_{p} \quad$ Annualized cost which includes other cost such as loss of opportunity, human resource

$T_{c f} \begin{gathered}i_{c}, w_{c} \\ c_{f}, t\end{gathered}$ Transportation cost for corn feedstock $c_{f}$ from supplier source $i_{c}$ to warehouse $w_{c}$ in time period $t$

$T_{m}^{i_{m}, w_{m}}$ Transportation cost for cellulosic feedstock $m_{f}$ from supplier $i_{m}$ to warehouse $w_{m}$ in time period $t$

$T_{c_{f}, t}^{w_{c}, k_{c}}$ Transportation cost for corn feedstock cffrom warehouse $w_{c}$ to biorefinery $k_{c}$ in time period $t$

$T_{m_{f}, t}^{w_{m}, k_{m}}$ Transportation cost for cellulosic feedstock $m_{f}$ from warehouse $w_{m}$ to biorefinery $k_{m}$ in time period $t$

$T_{c_{e}, t}^{k_{c}, t m}$ Transportation cost for corn ethanol $c_{e}$ from biorefinery $k_{c}$ to trade market $t m$ in time period $t$

$T_{m_{e}, t}^{k_{m}, c m}$ Transportation cost for cellulosic ethanol $m_{e}$ from biorefinery $k_{m}$ to market $t m$ in time period $t$

$d c_{c_{f}, t}^{i_{c}, w_{c}}$ Transportation distance for corn feedstock $c_{f}$ from supply source $i_{c}$ to warehouse $w_{c}$ in time $t$

$d c_{c_{f}, t}^{w_{c}, k_{c}}$ Transportation distance for corn feedstock $c_{f}$ from warehouse $w_{c}$ to biorefinery $k_{c}$ in time period $t$

$d c_{c_{e}, t}^{k_{c}, t m}$ Transportation distance for corn ethanol $c_{e}$ from biorefinery $k_{c}$ to trade market $t m$ in time period $t$

$d m_{m_{f}, t}^{i_{m}, w_{m}}$ Transportation distance for cellulosic feedstock $m_{f}$ from source $i_{m}$ to warehouse $w_{m}$ in time period $t$

$d m_{m_{f}, t}^{w_{m}, k_{m}}$ Transportation distance for cellulosic feedstock $m_{f}$ from warehouse $w_{m}$ to plant $k_{m}$ in time period $t$

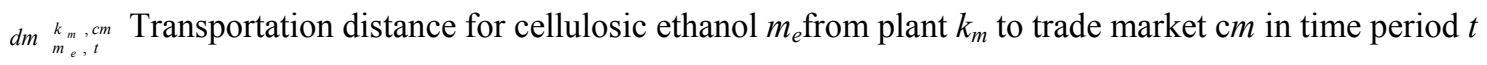

$\beta \quad$ Corn ethanolconversion rate

$\lambda \quad$ Cellulosic ethanol conversion rate

$\partial_{f l}$ Conversion factor from cellulosic feedstock to lignin at refinery plant

$\partial_{f p}$ Conversion factor from cellulosic feedstock to protein at refinery plant

$\nabla_{c d}$ Conversion factor from corn feedstock to DDGS at refinery plant

$\nabla_{c o}$ Conversion factor from cellulosic feedstock to corn oil at refinery plant

$W_{v} \quad$ Variable and fixed cost for warehouse cost for both cellulosic and corn feedstock

$C_{v} \quad$ Variable and fixed cost for biorefinery cost for both cellulosic and corn ethanol

$d_{c_{e}, t}^{t m} \quad$ Demand for corn ethanol $c_{e}$ at trade market $t m$ in time period $t$ 
$d_{m_{e}, t}^{c m} \quad$ Demand for cellulosic ethanol $c_{m}$ at cash market $m_{e}$ in time period $t$

$D_{t} \quad$ Total demand for cellulosic and corn ethanol at time period $t$

$\operatorname{Capf}_{\text {wco }} \min \quad$ Minimum fixed capacity of corn warehouse

Capf $_{\text {wco }}$ max Maximum fixed capacity of corn warehouse

Capf $f_{w c e} \min \quad$ Minimum fixed capacity of cellulosic warehouse

Capf wce max Maximum fixed capacity of cellulosic warehouse

Capfkco $\min \quad$ Minimum fixed capacity of corn biorefinery plant

Capf $_{\text {kco }}$ max Maximum fixed capacity of corn biorefinery plant

Capf $_{k c e} \min \quad$ Minimum fixed capacity cellulosic biorefinery plant

Capf $_{\text {kce }}$ max Maximum fixed capacity cellulosic biorefinery plant

Capv $v_{\text {wco }}$ min Minimum variable capacity of corn warehouse

Capv $_{\text {wco }}$ max Maximum variable capacity of corn warehouse

Capv wce $_{\text {min }}$ Minimum variable capacity of cellulosic warehouse

$C a p v_{\text {wce }}$ max Maximum variable capacity of cellulosic warehouse

Capv $_{k c o}$ min Minimum variable capacity of corn biorefinery plant

Capv ${ }_{k c o}$ max Maximum variable capacity of corn biorefinery plant

Capv $_{k c e} \min$ Minimum variable capacity cellulosic biorefinery plant

Capv $_{k c e} \max$ Maximum variable capacity cellulosic biorefinery plant

\section{Stochastic parameters}

$C_{c_{f}, t}^{\xi, i_{c}} \quad$ Uncertain cost of purchasing corn feedstock $c_{f}$ from supplier $i_{c}$ in time period $t$ under scenario $\xi$

$P_{c_{e}, t}^{\xi, t m} \quad$ Price of corn ethanol $c_{e}$ sold under scenario $\xi$ in time period $t$ to market $t m$

$C_{m_{f}, t}^{\xi, i_{m}}$ Uncertain cost of purchasing cellulosic feedstock $m_{f}$ from supplier $i_{m}$ in time period

$P_{m_{e}, t}^{\xi, t m} \quad$ Price of cellulosic ethanol $m_{e}$ sold under scenario $\xi$ in time period $t$ to market $t m$

$P c d_{c_{e}, t}^{\hbar, t m} \quad$ Price of DDGS

$P \mathrm{Co}_{c_{e}, t}^{\xi, t m} \quad$ Price of corn oil

$P l_{m, t}^{\xi, c m} \quad$ Price of lignin

$P p_{m, t}^{\xi, c m} \quad$ Price of protein

\section{First-stage decision variables}

$X c_{c_{f}, t}^{w_{c}} \quad$ Capacity of corn warehouse $w_{c}$ for pre-treating feedstock $c_{f}$ in time period $t$

$X c_{m_{f}, t}^{w_{m}} \quad$ Capacity of cellulosic warehouse $w_{m}$ for pre-treating feedstock $m_{f}$ in time period $t$ 
$\operatorname{Cap}_{k_{c}, t} \quad$ Production capacity of corn ethanol at plant $k_{c}$ in time period $t$

Cap $_{k_{m}, t}$ Production capacity of cellulosic ethanol at plant $k_{m}$ in time period $t$

\section{Second-stage decision variables}

$x_{i_{c}, t}^{w_{c}, \xi} \quad$ Amount of Corn feedstock purchased from source $i_{c}$ for warehouse $w_{c}$ at time period $t$ under scenario $\xi$

$x_{i_{m}, t}^{w_{m}, \xi} \quad$ Cellulosic feedstock purchased from source $i_{m}$ for warehouse $w_{m}$ at time period $t$ under scenario $\xi$

$S_{c_{e}, t}^{\xi, t m} \quad$ Amount of corn ethanol $m_{e}$ sold in scenario $\xi$ at time $t$ for trade market $t m$

$S_{m_{e}, t}^{\xi, t m} \quad$ Amount of cellulosic ethanol $m_{e}$ sold in scenario $\xi$ at time $t$ for trade market $t m$

$z_{k_{C}, t}^{t m, \xi} \quad$ Amount of corn ethanol produced at plant $k_{c}$ at time period $t$ for trade market $t m$ under scenario $\xi$

$z_{k_{m}, t}^{t m, \xi} \quad$ Amount of cellulosic ethanol produced at plant $k_{m}$ at time $t$ for trade market $t m$ under scenario $\xi$

$C L_{m_{e}, t}^{k_{m}{ }^{\xi}} \quad$ Amount of lignin produced from cellulosic feedstock at plant $k_{m}$ in time period $t$

$C P_{m_{e}, t}^{k_{m}, \xi} \quad$ Amount of protein produced from cellulosic at plant $k_{m}$ in time period $t$

$C D_{c, t}^{c, \xi} \quad$ Amount of DDGS produced from corn at plant $k_{c}$ in time period $t$

$C O_{c, t}^{k_{c} \xi^{5}} \quad$ Amount of corn oil produced from corn at plant $k_{c}$ in time period $t$

$X p_{c_{f}, t}^{w_{c}, \xi} \quad$ Pre-treated corn feedstock $\mathrm{c}_{f}$ available at warehouse $w_{c}$ in time period $t$ under scenario $\xi$

$X p_{m_{f}, t}^{w_{m}, \xi} \quad$ Pre-treated cellulosic feedstock $m_{f}$ at warehouse $w_{m}$ in time period $t$ under scenario $\xi$

$X c_{c_{f}, t}^{w_{c}, \xi} \quad$ Variable capacity of corn warehouse $w_{c}$ for pre-treating feedstock $m_{c}$ in time period $t$ under scenario $\xi$

$X c_{m_{f}, t}^{w_{m}, \xi} \quad$ Variable capacity of cellulosic warehouse $w_{m}$ for pre-treating feedstock $m_{f}$ in time period $t$ under scenario $\xi$

$\operatorname{Cap}_{k_{c}, t}^{\xi} \quad$ Variable production capacity of corn ethanol at plant $k_{c}$ in time period $t$ under scenario $\xi$

$\operatorname{Cap}_{k_{m}, t} \quad$ Variable production capacity of cellulosic ethanol at plant $k_{m}$ in time period $t$ under scenario $\xi$

\section{Index for hedging strategy}

$F \quad$ Denotes futures price symbol used on the trade market

$S \quad$ Denotes spot price symbol used on the trade market

tm Denotes the trade market

$\mathrm{cm}$ Denotes the cash market 


\section{Hedging strategy decision variables}

X

M

$Y_{\text {corn_fut }}(\xi)$

$Y_{\text {corn_spot }}(\xi)$

$Y_{\text {cell_fut }}(\xi)$

$Y_{\text {cell_spot }}(\xi)$

$X_{c_{f}, t m}^{F, t}$

$X_{m_{f}, \mathrm{~cm}}^{S, t}$

$H Z_{c_{e}, t m}^{, t}$

$H Z_{m_{e}, t m}^{F, t}$
The total amount of feedstock needed to be purchased (both corn and cellulosic)

Dummy variable

Binary decision to buy cornunder futures hedging strategy

Binary decision to buy cornunder spot hedging strategy

Binary decision to buy cellulosic under futures hedging strategy

Binary decision to buy cellulosicunder spot hedging strategy

The amount of corn feedstock $c_{f}$ for hedgingpurchased at futures price $F$ in time period $t$

The amount of cellulosic feedstock $m_{f}$ for hedgingbought at spot price $S$ in time period $t$

The amount of corn ethanol $c_{e}$ produced for hedging at time period $t$ for cash market t $m$

The amount of cellulosic ethanol $m_{e}$ produced for hedging at time period $t$ for cash market $t m$

\section{Hedging strategy parameters}

$P X_{c_{f}, t m}^{F, t} \quad$ Futures price of corn feedstock $c_{f}$ in market $t m$ at time period $t$ at futures price $F$

$P X_{m_{f}, \mathrm{~cm}}^{S, t} \quad$ Spot price of cellulosic feedstock $m_{f}$ for hedgingpurchased at spot price $S$ in time period $t$

$P z_{c_{e}, t m}^{F, t} \quad$ Futures price for selling corn ethanol $c_{e}$ when taking the position at time period $t$ at futures market $F$

$P z_{m_{e}, \mathrm{~cm}}^{F, t} \quad$ Futures price for selling cellulosic ethanol $m_{e}$ for hedgingpurchased at spot market $S$ in time period $t$

$S X_{c_{f}, t m}^{F, t} \quad$ Spot price of corn feedstock

$A v g\left(P X_{c_{f}, t m}^{F, t}\right)$ Average price of corn futures price

cpo Cost of brokerage, margin calls and interest rates for corn future long position (buying corn)

$\alpha \quad$ Heuristic value for hedging strategy

\section{Copyrights}

Copyright for this article is retained by the author(s), with first publication rights granted to the journal.

This is an open-access article distributed under the terms and conditions of the Creative Commons Attribution license (http://creativecommons.org/licenses/by/3.0/). 